\title{
Laboreal
}

Volume $10 \mathrm{~N}^{\circ} 2$ | 2014

Análise ergonómica do trabalho e formação - Parte II

\section{A análise do trabalho trinta anos após Ombredane e} Faverge

El análisis del trabajo treinta años después de Ombredane y Faverge

L'analyse du travail trente ans après Ombredane et Faverge

Work analysis thirty years after Ombredane and Faverge

\section{Guy Karnas e Pierre Salengros}

\section{(2) OpenEdition}

12 Journals

\section{Edição electrónica}

URL: http://journals.openedition.org/laboreal/4993

DOI: $10.4000 /$ laboreal.4993

ISSN: 1646-5237

\section{Editora}

Universidade do Porto

Refêrencia eletrónica

Guy Karnas e Pierre Salengros, «A análise do trabalho trinta anos após Ombredane e Faverge », Laboreal [Online], Volume 10 N² | 2014, posto online no dia 01 dezembro 2014, consultado o 24 setembro 2020. URL : http://journals.openedition.org/laboreal/4993 ; DOI : https://doi.org/10.4000/ laboreal.4993

Este documento foi criado de forma automática no dia 24 setembro 2020.

Laboreal está licenciado com uma Licença Creative Commons - Atribuição-NãoComercial 4.0 Internacional. 


\title{
A análise do trabalho trinta anos após Ombredane e Faverge
}

\author{
El análisis del trabajo treinta años después de Ombredane y Faverge \\ L'analyse du travail trente ans après Ombredane et Faverge \\ Work analysis thirty years after Ombredane and Faverge
}

Guy Karnas e Pierre Salengros

\section{REFERÊNCIA}

Karnas, G., \& Salengros, P (1986). L'analyse du travail trente ans après Ombredane et Faverge. In R. Patesson. L'Homme et l'écran. Aspects de l'ergonomie en informatique (p. 331-340). Colloque “ L'ergonomie en informatique », 1985, Nivelles. Bruxelles : Ed.de l'Université de Bruxelles.

\section{NOTA DO EDITOR}

http://dx.doi.org/10.15667/laborealx0214kspt

Passaram então trinta anos desde que a Presses Universitaires de France (PUF) publicou a obra de OMBREDANE e FAVERGE dedicada à análise do trabalho, que abordava, essencialmente, as conferências feitas no Seminário de Análise do Trabalho da Université Libre de Bruxelles (U.L.B.) por Faverge em 1953 e 1954. Nesta obra que demonstrava sobretudo a pertinência da construção de uma metodologia adaptada a cada atividade profissional, encontrávamos todas as bases de uma corrente que, nos países francófonos e em vários países do Leste, passou a ser chamada de ergonomia psicológica, opondo-se aos modelos restritivos e estritamente experimentalistas da Human Engineering americana, e que reconciliava a análise do homem e a da sua atividade, integrando a maioria dos grandes capítulos da psicologia do pessoal, ou seja :

- A seleção, orientação e promoção profissional ; 
- A formação profissional ;

- A qualificação do trabalho.

São estas as finalidades essenciais da análise do trabalho que encontram como primeira dificuldade a que De Montmollin realçava na conferência inaugural: A análise do trabalho é, com efeito, simultaneamente, método e objeto. Assim, só pode ser concebida através da referência a um objetivo, em relação ao qual é "método".

Os problemas metodológicos levantados pela análise do trabalho só podem ser resolvidos através do recurso a outros métodos, e todas as exposições desta tarde terão tendência a apresentar os principais métodos utilizados com as respetivas implicações em geral e no caso particular da informática.

Do ponto de vista destes métodos, e mantendo-nos o mais perto possível do seu texto, Faverge crítica de forma veemente na Análise do Trabalho aquilo a que ele chama de "método ensaísta", ou seja, a análise do trabalho em termos de aptidões por decomposição em operações, ou ainda pelo recurso exclusivo ao inquérito junto das chefias.

6 Indo contra estas práticas, ele indica a necessidade de apresentar e colocar claramente o problema estudado e definir sem ambiguidade o objetivo do estudo. Estas duas premissas determinam a escolha dos "critérios que permitirão confirmar o valor da solução proposta para o problema colocado".

7 A questão torna-se em definitivo a das relações subjacentes à análise do trabalho, entre o objetivo, o conteúdo e o modo (ou ainda entre as finalidades, o objeto e a técnica).

8 Em 1955, Faverge enfatizou sobretudo o que diz respeito ao conteúdo: A informatização, a língua das comunicações (mais do que um capítulo foi dedicado a este tema e toda a obra revela a importância para Ombredane e Faverge da informação, dos sinais utilizados no trabalho). É assim que ele realça que uma boa parte da atividade de analista do trabalho será dedicada à explicação, à compreensão destes sinais, da passagem de sistemas de sinais a outros, etc...

9 Com "a adaptação da máquina ao homem" que inaugura em 1958 a coleção "Le psicologue", Faverge implementa as duas primeiras abordagens da ergonomia, a gestual e informacional.

10 Foi após 1972, ou seja, após as pesquisas apoiadas pela CECA (Comunidade Europeia do Carvão e do Aço) primeiro, depois pela OBAP (Organismo Belga para o Crescimento da Produtividade), que se vai restabelecer o conteúdo informacional do trabalho em relação aos outros, indicando objetos ou níveis de análise que mantêm atualmente toda a sua pertinência e que chamámos de quatro abordagens da ergonomia, que são apenas citados, para quem ainda não esteja familiarizado com eles.

- Trabalhar é ocupar-se das posturas, realizar gestos ;

- Trabalhar é tratar a informação, é "comunicar" com a matéria, seja diretamente ou com a ajuda de intermediários mais ou menos complexos, desde o painel, botão, pedal, até ao computador ou robô, passando pelo autómato ;

- Trabalhar é também regular processos complexos originados, nomeadamente, a partir de interações entre as células de um sistema em que nós mesmos somos um dos elementos (isso é evidente) que é também um sistema ; 
- Finalmente, trabalhar é recorrer a processos de pensamento que gerem as atividades anteriores. Assim, é implementar algoritmos, heurísticas, representações, estratégias. É esse o domínio que passou a ser a ergonomia cognitiva.

11 Tal como Faverge reparou, as quatro "análises que resultam da constatação da existência dos quatro componentes do trabalho citados podem ser feitas e completamse mutuamente, mas têm importâncias desiguais, de acordo com a natureza do trabalho e dos objetivos do estudo". O que é importante é realçar que estas quatro abordagens "aparecem", na verdade, historicamente pela ordem em que foram citadas, em função de uma certa evolução resultante de modificações tecnológicas e ergonómicas.

12 Atualmente, onde é que nos encontramos? Junto das indicações destes autores, gostaríamos de insistir aqui brevemente em três pontos particulares, tendo consciência de que se trata de uma escolha entre muitas outras.

o primeiro ponto diz respeito ao contexto no qual a análise do trabalho deve ter lugar atualmente, e gostaríamos de realçar algumas das suas características. Estas características progrediram juntas, se bem que não seja simples desembaraçar o novelo. Distinguimos a tomada de poder do homem sobre a sua atividade, os movimentos de humanização do trabalho e o rápido desenvolvimento das técnicas informáticas no âmbito de uma crise económica com as suas consequências na dinâmica organizacional da empresa.

\section{$\left.1^{\circ}\right)$ A tomada de poder do homem sobre a sua atividade}

15 Numa pesquisa já antiga levada a cabo na altura de uma primeira automatização de um serviço do tipo bancário, chamou-nos a atenção o jogo de manipulações recíprocas dos empregados e da organização. O número de empregados a colocar diariamente em linha depende do volume das ordens recebidas, e este volume é particularmente variável de um dia para o outro. A atividade de previsão parece o enredo da atividade global e a fonte de fenómenos de atitude das pessoas no trabalho. A previsão é realizada, não por uma célula de gestão, mas por uma única pessoa, que conhece perfeitamente as potencialidades das unidades de trabalho e os fatores que têm repercussões sobre a atividade.

16 O estudo do comportamento deste homem revela ao mesmo tempo um conhecimento preciso do número de documentos esperados (tendo em conta os dias da semana, do mês, do período do ano, de dias de férias...), mas também uma manipulação desta previsão de acordo com as normas que é possível distinguir: reparamos numa sobreavaliação sistemática da previsão para os dias de fraca ou média atividade e, pelo contrário, uma subavaliação para os dias de forte atividade.

17 Esta política deliberada deu origem a uma estabilização do número de ordens numa zona média.

No entanto, a falta de realismo na previsão é intencional: a variável com que a organização "joga" é o número de trabalhadores a colocar em linha para absorver uma quantidade de trabalho, de que se sabe que ela sobre ou subavaliada. A estratégia será diferencial e conduzirá a uma otimização no sentido do pessoal ; se o trabalho tiver sido sobreavaliado, muitos trabalhadores sairão do trabalho mais cedo, recuperando horas 
de férias que serão compensadas ao longo de outros dias com mais trabalho. A variabilidade do trabalho é assim minimizada nos seus efeitos mais importantes, em benefício da dinâmica organizacional ; ainda mais, alguns inconvenientes tradicionais típicos da arquitetura administrativa são eliminados enquanto os reencontramos, se simularmos outras maneiras de efetuar o trabalho, por exemplo, se calcularmos o número de ordens a tratar a partir do dia da semana, da semana, do mês...

Os membros do pessoal adaptam as suas estratégias pessoais a esta previsão. Eles são capazes, mal chegue o trabalho, de avaliar a importância da sua carga laboral e optam por uma estratégia que os faça sair da instituição de modo precoce ou tardio.

Esta tomada de poder é admirável e muito frequentemente optimiza o interesse da organização ao lado do interesse do trabalhador, mantendo frequentemente um valor lúdico na atividade.

21 Assim acontece na análise levada a cabo por um de nós das estratégias dos controladores da venda de lugares no avião numa empresa aérea. Se nos lembrarmos que a empresa aérea só tem lucro a partir do momento em que o avião está suficientemente cheio para assegurar a rentabilidade do voo, o controlador é chamado a proceder ao "overbooking", ou seja, a vender um número de lugares superior ao número teórico de lugares disponíveis, pois a experiência mostra que um certo número de passageiros anula o seu voo antes da partida.

A estratégia adoptada permite ao controlador aumentar o que vamos chamar de sua autonomia de decisão em relação às ordens emitidas pelo sistema - o "space control" no qual ele se insere; as decisões de conceder um volume maior ou menor de "overbooking" têm em conta a o carácter precoce do pedido, a existência de reserva por grupos de clientes... e outras variáveis também; o trabalho manual substitui o procedimento automático e devolve ao mesmo tempo benefício pessoal ao homem e o benefício organizacional e económico à instituição.

Observamos que, se esta tomada de poder for frequentemente evidenciada nos trabalhos informatizados ou em curso de informatização, é porque aqui o homem pode "jogar", provavelmente, verdadeiramente contra a máquina, para demonstrar à organização a aberração da sua substituição por esta, e contribui com efeito de uma forma que a máquina não pode assegurar, tal como foi mostrado noutros exemplos.

\section{$\left.2^{\circ}\right)$ Os movimentos de humanização do trabalho e respetivos corolários}

24 Junto com a metodologia um pouco isolada intencionalmente do seu contexto proposta por Ombredane e Faverge, uma evolução sociológica, política e económica agiu como tal para desenvolver a corrente por vezes qualificada de humanização do trabalho. Este movimento, concorrente ao movimento animado de preocupações ergonómicas mais funcionais, levou a atribuir maior atenção às condições de trabalho do homem, logo, para as exigências do trabalho, para a sua adaptação ao operador humano, ou seja, em definitivo para a necessidade de uma análise do trabalho.

Nesta perspetiva, e paralelamente às contribuições psicossociológicas muito estudadas, o estudo das condições de trabalho parece conduzir a uma nova interpretação do trabalho na ótica do trabalhador. 
26 Até aqui, o trabalho era visto como uma entidade em si na qual o indivíduo estava comprometido com um contrato limitado quanto à sua implicação pessoal. equilíbrio entre as duas vidas como condição de harmonia e satisfação, é necessário sobretudo compreender que a sua ancoragem recíproca contribui com um novo ponto de vista para o problema das representações do trabalho para o homem, como para o dos sistemas de valores que ele transmite ; assim, podem ser analisados vários conceitos derivados: no caso de concordância entre as duas vidas, o do alargamento horizontal ou vertical das tarefas de enriquecimento, reestruturação do trabalho, interesse pelas experiências industriais como pelos grupos semi-autónomos onde a participação voluntária tem uma nova definição da organização do trabalho. No caso de rivalidade temporal entre a vida no trabalho e a vida fora do trabalho, há possibilidades de reinterpretação dos limites de declaração de acidentes ou de fatores que influenciam o absentismo. Nestas duas circunstâncias, reparamos numa nova interpretação do trabalho através de uma tipologia dos estilos profissionais do homem, que constitui assim uma segunda ideia que desejamos desenvolver.

31 A noção de "estilo" apresenta várias vantagens quando estudamos a motivação do homem no trabalho: a antiga noção de necessidade fazia mais referência a uma avaliação quantitativa (a necessidade é satisfeita ou não), a de uma realização ou expectativa, era mais positiva, visto que implicava um projeto pessoal, a noção de "objetivo" fazia, por sua vez, referência à busca por um desempenho, em que um objetivo era atingido ou não ; o conceito de estilo introduz atualmente a multiplicidade dos objetivos ou expetativas; o objetivo em que o sucesso deixa de ser o critério do homem enquanto tal, mas diferentes trabalhadores podem procurar e atingir objetivos distintos. A unidade aqui deixa de ser a do analista que contribui com os seus critérios e com a sua maneira de avaliar e torna-se a do próprio trabalhador; o objetivo é visto aqui mais pelo homem do que pela organização. Definir o estilo de um homem na sua vida profissional como o conjunto organizado dos seus comportamentos refletindo a sua conceção pessoal da vida no trabalho, esta definição pode ser estendida à vida fora do trabalho, comprometendo-se o nosso laboratório com a análise e definição de tipologias de estilos em âmbitos profissionais diferentes.

Quer se trate de operários, monitores de formação profissional de adultos, estudantes ou ergónomos, podemos caraterizar modos distintos e coerentes de se comportar na 
atividade em questão ; esta coerência é aliás confirmada pelo recurso a técnicas de formalização, como a análise tipológica e a análise fatorial.

O ângulo sobre o qual a ergonomia considera o trabalho é aqui invertido em relação à conceção clássica : o sujeito fala para ele, mas isso só pode ser efetuado mediante uma modificação de métodos na abordagem ao problema: a entrevista e as perguntas substituem a observação e a análise da atividade. Reparamos que estas técnicas acompanham o movimento já realçado da influência do homem no seu trabalho, de um maior respeito concedido à interação psicossocial entre o analista e o analisado ; esta deslocação metodológica pode conduzir a novas dificuldades na interpretação dos resultados, visto que, ao contrário das técnicas de investigação diretas, estas estão sujeitas à manipulação.

\section{$\left.3^{\circ}\right) 0$ desenvolvimento das técnicas informáticas no contexto de uma crise económica}

As consequências da política de informatização das empresas começam a aparecer no setor terciário, nomeadamente na banca, e atualmente é possível medir algumas recaídas que podem ser momentâneas: para os sujeitos direta e continuamente confrontados com a codificação de dados nos serviços centrais, há o sentimento de submissão à máquina, perda de graus de liberdade no que diz respeito a procedimentos, execução e tempo de trabalho, perda de emprego, sentimento de perda de autonomia na relação com a máquina; para os empregados que trabalham em agências em contato com o público, há problemas particularmente cruciais de dependência com a máquina, sentimento de despersonalização na relação com os clientes...

o quadro que o investigador traz a partir da sua observação destes procedimentos é mais frequentemente opaco no estado atual das coisas; o mais grave é, sem dúvida, o facto dos procedimentos ergonómicos que são atualmente objeto de estudo, que embora teoricamente resolvidos, assentam ainda mais frequentemente numa primeira adaptação à máquina, por exemplo, através de um estudo da luminescência dos discos, através da forma ou disposição dos carateres, por estudos de iluminação ou contraste.

As pesquisas começam apenas a basear-se nos aspectos psicossociológicos da relação do homem com a máquina, por exemplo, através da elaboração de programas mais flexíveis, melhor adaptados aos operadores no sentido em que podem integrar o seu procedimento pessoal de análise, a sua criatividade e a sua personalidade ; atualmente, são propostas tentativas neste sentido por razões evidentes de produtividade e respeito pelos procedimentos, não tendo ainda saído realmente dos laboratórios.

Eis um exemplo de estudo realizado numa instituição bancária :

O posto estudado é um posto de digitação de dados. O estudo é feito enquanto ocorre uma grande mudança tecnológica. Os trabalhadores têm como missão codificar os dados relativos às operações bancárias transmitidas para a sede central. Os dados são registados em bandas magnéticas através de um terminal. Até agora, os dados eram fornecidos às operadoras sob forma de fichas que ficavam num monte ao longo do dia. Agora, é proposto que apareça sequencialmente uma imagem das fichas em vídeo.

A análise do trabalho assenta essencialmente numa situação anterior. Ela permitiu evidenciar uma regulação do rendimento em função da quantidade de trabalho prevista 
para o dia (a quantidade de documentos a tratar varia muito de um dia para o outro, e o tempo de presença no trabalho também varia).

Um exame mais preciso dos dados recolhidos pela análise tipológica mostra a existência de subgrupos de operadoras. Na verdade, enquanto que algumas diminuem o seu rendimento à medida que o dia vai passando, outras aumentam e outras não mudam em nada.

Parece claro que estas regulações encontram a sua fonte na possibilidade que as operadoras têm em avaliar a qualquer momento o trabalho feito e a tarefa que falta fazer. Analisando então as reticências das trabalhadoras à mudança do seu posto de trabalho, o autor conclui que a perda da possibilidade de avaliar o trabalho que falta fazer e, consequentemente, de controlar o seu posto, a sua atividade, o controlo da incerteza em que se encontra, está na base das resistências.

Segundo ponto: neste quadro em que o homem procura e tem a possibilidade de modificar a sua atividade em relação ao prescrito, a análise do trabalho deve distinguir a análise da tarefa e a análise da atividade, ou ainda condutas operatórias.

Distinguimos na análise o quê e o como. O que há a fazer e como é que os trabalhadores o fazem?

A análise da tarefa, descritiva e diagnóstica, contém :

(1) A situação da tarefa no seu contexto ;

(2) A descrição da tarefa (objetivos, princípios de construção do dispositivo, regras de funcionamento, programa de funcionamento);

(3) A descrição em referência às variáveis em que pudemos mostrar a influência no comportamento do operador (como os constrangimentos, os fatores de infiabilidade...).

A análise da atividade distingue essencialmente os aspetos observáveis, por um lado, e por outro lado, os mecanismos que regem a organização destes últimos, ou seja, a regulação da atividade (aspetos percetivos, tratamento das informações, incluindo a análise dos erros e da sua criação).

Esta distinção entre a análise de tarefas e a análise da atividade, Leplat situa-a em 1980 em relação a outra que coloca a atividade no centro de uma corrente que tem a montante as condições que a determinam (as condições de trabalho) e a jusante, as consequências que a atividade terá para o trabalhador e para o sistema.

Do lado das condições, definimos classicamente as condições internas e as condições externas: ou seja, por um lado, as caraterísticas do trabalhador (antropométricas, estado orgânico, idade, sexo, qualificações, experiência, formação, personalidade, etc...), por outro, as caraterísticas do ambiente de trabalho (condições físicas, técnicas, organizacionais, socioeconómicas...).

51 Neste contexto, e de acordo com Leplat, a atividade aparece como "a resposta do indivíduo ao conjunto destas condições. Ela pode aplicar-se, por um lado, ao próprio corpo ou a objetivos materiais e, por outro, a representações. No primeiro caso, falamos da atividade física ou manual e esta atividade será observável. No segundo caso, falamos da atividade representativa ou mental (ou ainda cognitiva ou intelectual), a atividade inobservável deverá ser deduzida a partir de diversos traços".

52 Terceiro ponto e conclusão do silogismo dos dois primeiros pontos citados : a análise da tarefa e a análise da atividade apresentam uma metodologia específica. 
53 No que diz respeito à tarefa, Sperandio (1984) propõe os seguintes pontos, que devem necessariamente comportar a análise :

- Delimitação do sistema homem-máquina em que estamos interessados.

- Elaboração de um "esboço conjunto" que definirá o operador, máquina, informações, ações.

- Descrição dinâmica do funcionamento do sistema.

- Identificação das exigências de trabalho.

- Determinação dos eventuais disfuncionamentos.

Para lá chegar, iremos recorrer a técnicas variadas, como :

1. Esquemas espaciais (modelos de organização espacial).

2. Os esquemas em termos de encaminhamento das informações.

3. Modelos de organização sequencial :

1. Diagrama das sequências operacionais.

2. Organigrama.

4. Modelos de organização das interações.

5. Modelos do tipo catálogo de funções.

6. Catálogos das funções humanas praticadas.

7. Identificação das exigências para o operador (como as grelhas LEST, SAVIEM, Método dos perfis dos postos RENAULT).

8. Taxonomia dos disfuncionamentos.

9. Esquemas de processos.

10. Esquemas da organização homem-máquina.

11. Esquemas funcionais homem-máquina.

Por comparação, Faverge propunha num capítulo "Como conduzir uma análise do trabalho", três modos de análises próximas da análise da atividade do operador, ou seja :

1. A aprendizagem pessoal.

2. A observação do operário durante o seu trabalho.

3. Estudo dos traços do trabalho.

Aos quais associava algumas técnicas hoje clássicas de recolha de informação útil para os métodos:

1.1. Os métodos gráficos dos organizadores e especialistas do estudo dos tempos.

1.2. A amostragem do trabalho.

59 1.3. A técnica dos incidentes críticos de Flanagan.

60 2. A utilização de aparelhos de registo e

61 3. A experimentação em laboratório.

62 As técnicas utilizadas atualmente constituem variantes e prolongamentos desta enumeração. 


\section{BIBLIOGRAFIA}

Faverge, J.M. \& Al (1958). L'adaptation de la machine à l'homme, Presses Universitaires de France, Paris.

Faverge, J.M. \& Al (1966). L'ergonomie des processus industriels, Editions de l'Institut de Sociologie, U.L.B., Bruxelles.

Faverge, J.M. \& Al (1972). L’analyse du travail, en Traité de Psychologie Appliquée - tome 3, Presses Universitaires de France, Paris.

Faverge, J.M. \& Al (1970). L'organisation vivante, Editions de l'Institut de Sociologie, U.L.B., Bruxelles.

Karnas, G. (1985). L'analyse du travail, ronéo, Bruxelles.[1]

\section{NOTAS}

1. Nota do Comité Editorial: Este texto é anterior ao seguinte : Karnas, G. (1987). L'analyse du travail. In C. Levy-Leboyer \& J.C. Sperandio (ed.), Traité de psychologie du travail (pp. 609-625). Paris : PUF.

\section{RESUMOS}

A análise do trabalho de Ombredane e Faverge desenvolvida em 1955, apresentava uma metodologia original que conjugava a seleção, a formação e a qualificação do trabalho com a transformação deste.

Os autores explicitam três ideias que emergiram desde aí e que fundamentam ainda as pesquisas na matéria : A análise do trabalho deve fazer a distinção entre a análise da tarefa e a análise da atividade. Estas duas análises apresentam uma metodologia específica, e toda a análise do trabalho deve ter em conta novos fatores que agem em interação, quer na tomada de poder do homem sobre a sua atividade ou sobre a sua tarefa, a influência da crise económica e as suas consequências, e o desenvolvimento das técnicas informáticas e o que delas resulta.

\section{AUTORES}

\section{PIERRE SALENGROS}

Université Libre de Bruxelles, Laboratoire de Psychologie Industrielle et Commerciale, Avenue F. Roosevelt, 50, 1050 Bruxelles, Belgique 